\title{
Proceeding
}

Supplementary Issue: Spring Conferences of Sports Science. Costa Blanca Sports Science Week, 26-28 April 2018. Calpe. Alicante, Spain

\section{Reaction of vegetative nervous system to loads in female long-distance runners with different fitness level}

\author{
VLADISLAV BAKAYEV1 1 , ALEXANDER BOLOTIN ${ }^{1}$, CHUNGUANG YOU² \\ ${ }^{1}$ Institute of Physical Education, Sport and Tourism, Peter the Great St. Petersburg Polytechnic University, \\ Russia \\ 2Linyi University, Shandong, China
}

\begin{abstract}
In the course of research it was established that the female runner A with the high degree of vegetative nervous system parasympathetic division activity and the low degree of activity of the central regulation mechanisms with the increased activity of subcortical nervous centres had considerable advantage over the female runner B with high activity of the vegetative nervous system sympathetic division. The high activity of the central control structures taking into account the increased vegetative nervous system parasympathetic division activity in the female runner $A$ indicates the high reserve capacity of the organism and the economical energy consumption during the running loads. It was revealed that the dynamics of heart rate regulation after the functional tests with physical loads is manifested in the change of the vegetative nervous system parasympathetic division tonicity. It affects the time-period of respiratory waves manifestation. The female runner $A$ with the high fitness degree demonstrated the decreasing time-period compared to the female runner B with the low level of fitness. Key words: VEGETATIVE NERVOUS SYSTEM, EVALUATION OF THE RESERVE CAPACITY OF THE ORGANISM, FEMALE LONG-DISTANCE RUNNERS, FITNESS LEVEL, ACTIVITY OF THE PARASYMPATHETIC AND SYMPATHETIC DIVISIONS.
\end{abstract}

Cite this article as:

Bakayev, V., Bolotin, A., \& You, C. (2018). Reaction of vegetative nervous system to loads in female longdistance runners with different fitness level. Journal of Human Sport and Exercise, 13(2proc), S245S252. doi:https://doi.org/10.14198/ihse.2018.13.Proc2.09

Corresponding author. Institute of Physical Education, Sport and Tourism, Peter the Great St. Petersburg Polytechnic University, Russia. http://orcid.org/0000-0001-9455-9662

E-mail: vlad.bakaev@gmail.com

Supplementary Issue: Spring Conferences of Sports Science. Costa Blanca Sports Science Week, 26-28 April 2018. Calpe. Alicante, Spain.

JOURNAL OF HUMAN SPORT \& EXERCISE ISSN 1988-5202

(c) Faculty of Education. University of Alicante

doi: 10.14198/jhse.2018.13.Proc2.09 


\section{INTRODUCTION}

Currently the conditions of competitive exercises make increased demands on the status of cardiovascular system of female runners in long-distance running. It is possible to assess the state of the cardiovascular system of female runners on the heart rate variability. Change of the heart rhythm is a universal quick response of the whole body of female athletes in regard to the influence of training physical load. At the same time, different combinations of activity elements that provide vegetative homeostasis of the heart rhythm can correspond to the same heart rate. The measurement of the average pulse rate gives the opportunity to assess only the final results of the regulation activity mechanisms of the heart rhythm. The activity of the regulation mechanisms of the heart rhythm itself is shown in the variability of the RR-intervals (Bolotin, \& Bakayev, 2017; Bunevicius, et al., 2016; Cooper, 1989; Daniel, 2009; Bakaev, et al., 2015; Willardson, 2007).

In the normal state of the cardiovascular system of female runners for the long distances, the period between two adjacent cardiac contractions varies from contraction to contraction. This variability is the heart rate variability. The variability of the heart rhythm submits to various regularities which can be revealed and estimated quantitatively. These regularities can be shown differently in the time intervals of various activity (from a few seconds to 24 hours and more) and under the various conditions (at rest, at the controlled physical loadings, etc.) (Bakaev et al., 2016; Bolotin, \& Bakayev, 2016; Hopkins, et al., 2009; Khimenes, et al., 2016; Pityn, et al., 2017).

The heart rhythm regulation in female runners is in the cardiac sinus node via the complicated nervous and humoral mechanisms. The cardiac sinus node can be considered as the indicator of a physical state of the female runners (Bolotin, \& Bakayev, 2017; Bunevicius, et al., 2016; Daniel, 2009; Matveyev, 1981).

It is known that dynamics of heart rhythm regulation after the functional tests with the physical activity is shown in change of the parasympathetic department tone of the autonomic nervous system. This affects the time of respiratory wave manifestation. Therefore the studying of dynamics of values of manifestation time of respiratory waves in the female athletes with the different degree of physical training is an important scientific task. The solution of this task will allow to assess the degree of adaptation of female runners for the long distances to the training physical load.

Research goal is to compare dynamics of values of respiratory waves' recovery time in female athletes with the different degrees of physical training after the controlled physical load.

Research objects. To compare the recovery rate of respiratory waves at female athletes with the different degrees of physical training after the controlled physical load.

To reveal how the recovery rate of respiratory waves at female athletes with the different degrees of physical training can be used for assessment of the adaptation degree of the female runner's body to physical load.

\section{MATERIAL AND METHODS}

Here were studied two female athletes $A$ and $B$, running for the long distances. The first three training microcycles were taken for comparison in the initial period of preparation for the competition. During the three first training micro-cycles both female athletes had the same quantity, volume and intensity of running physical 
load. Every day 300 RR-intervals were taken twice a day at rest and once under the influence of training exercises. The obtained data were analysed and exposed to the further all-round statistical processing.

The fractal analysis of the heart rate variability in female runners for the long distances was carried out during the research. The quantitative and qualitative study and comparison of the time series of RR-intervals was carried out in female athletes $A$ and $B$ to determine the effectiveness of the fractal components functioning in the blood circulatory system.

The components characterizing the cardiac function (A1 and A2) as such, the neurovegetative component (B1 and B2), the status of the pituitary-hypothalamic system (C1 and $C 2$ ) and the central nervous system (D1 and D2) were assigned to the values of the fractal analysis of the heart rhythm. The values of fast (nervous) regulation (FRV) included A1, B1, B2, C1, D1 values, and the values of slow (hormonal) regulation (SRV) included A2, C2, D2 values.

During the research were studied: A1 - the combined regulation effect; $A 2$ - a value of own cardiac regulation; $\mathrm{B} 1$ - a value of the vegetative homeostasis of the heart rhythm; $\mathrm{B} 2$ - a value of regulation stability of the heart rhythm; $\mathrm{C} 1$ - a value of regulation level of pituitary-hypothalamic system (a nervous regulation component); $\mathrm{C} 2$ - a value of regulation level of pituitary-hypothalamic system (an endocrine regulation component); D1 - a value of the "fast" adaptation to exercise load; D2 - a value of the "slow" adaptation to exercise load.

Based on the obtained data the neurodynamic analysis of the heart rhythm was carried out in female athletes with the use of the neurodynamic pyramid construction. The values in the left part of the pyramid - anabolism, and in the right part - catabolism were assigned to the indices of the neurodynamic pyramid. The ratio of the left and right parts of the neurodynamic pyramid characterized the dynamics of anabolic and catabolic processes in the body of female athletes under the influence of the training load. The left part was proportional to time of energy resources accumulation, and the right part - to time of energy resources consumption. It was considered that the more is the volume of the energy pyramid, the less is the level of the energy consumption for the same work at female athletes. It corresponded to the minimum participation of this regulation level in the regulation of the heart rhythm in female athletes.

The data on the characteristic of the heart rate rhythm were obtained with the help of the "VNS-Rhythm" device on the basis of calculation and evaluation of statistical parameters of the time series of RR intervals, variation pulsometry, and autocorrelation analysis. They are represented by the complex of values in the form of statistical characteristic of the time series of cardiac intervals, the R-R intervals histogram, autocorrelogram and spectral analysis of heart rate variability. For processing of the cardiointervalogram and analysing of the heart rhythm variability was used the "Varicard 2.51 " device.

The statistical characteristic of time series of the cardiac intervals was estimated by the standard deviation normal to normal (SDNN). The standard deviation normal to normal (SDNN) indicated the combined effect of the physical load influence on the sinus node of sympathetic and parasympathetic departments of the autonomic nervous system of female athletes. The increase in SDNN demonstrated an increase in the tone of parasympathetic department of the autonomic nervous system. The SDNN value was an extremely sensitive indicator for assessment of the status of the heart rhythm regulation mechanisms in the female athletes. The increase of SDNN indicated the strengthening of autonomous regulation, in other words on the breath influence degree on the working heart rhythm of the female athletes. We connected the SDNN reduction with the strengthening of sympathetic regulation of the heart rhythm. 
The histogram of R-R intervals or variational pulsometry was estimated by the number of numerical characteristics. Numerical characteristics of the variational pulsometry were: mode (Mo), range (AH) and amplitude of the mode (AMo).

It was studied an amplitude of the mode (AMo) which represented the percent from the total number of cardiointervals. The AMo value reflected the stabilizing effect of centralization of the heart rhythm control. This value has been caused by the degree of the sympathetic department activity of the autonomic nervous system of the female athletes. It was considered that together with the increase of AMo values there is a strengthening of sympathetic regulation of the heart rhythm of the female athletes.

The use of autocorrelogram was directed to studying the internal structure of the time series of cardiointervals. The autocorrelogram was presented as the schedule of dynamics of the correlation coefficients. It determined the nature of dependence between the consecutive rows of $R-R$ intervals and represented the changes of the wave structure parameters of heart rhythms. Using the autocorrelogram values was assessed the degree and the nature of influence of the central mechanisms on the process of self-control of the cardiac function.

The steepness values of the autocorrelogram - $\mathrm{kk}$ (the value of the autocorrelation function at the first shift) and the decay rate - mo (the shift of the autocorrelation function on which it became negative in the first time). The colligation degree and the type of the dependence between the central and autonomous heart rate control loops were revealed by means of an autocorrelogram.

The spectral analysis of heart rhythm variability was used during the research. Application of the spectral analysis allowed to quantify the various frequency components of the heart rhythm fluctuations and to represent graphically the ratios of different components of the heart rhythm which reflect the activity of certain parts of the regulatory mechanism. The following spectral components were investigated: high-frequency (HF), low-frequency (LF), very low-frequency (VLF). It was considered that the main component of HF waves is the vagal activity; LF waves characterize a status of sympathetic department of the autonomic nervous system; VLF waves are the sensitive indicator of the control of metabolic processes.

During the statistical processing of the obtained data took place a calculation of the arithmetic mean value $(\mathrm{x})$; of the standard quadratic deviation $(\mathrm{G})$; of the standard error of arithmetic mean value $(\mathrm{m})$; of the calculation of statistical significance for Student's t-test $(P)$.

\section{RESULTS AND DISCUSSION}

The assessment of the stress state of regulatory systems of the heart rhythm in female athletes at rest was carried out during the research. For this purpose were studied the main parameters of the heart rate variability in female athletes for long distance running. Data of the heart rate variability of female athletes at rest are presented in the Table 1.

While analysing the data of heart rate variability presented in Table 1, it can be noted that the female athlete A has more expressed activity of the parasympathetic nervous system (SDNN) and slow wave structure (HF, $L F, V L F)$ compared to the female athlete $B$. That is grounds for affirming that the female athlete $A$ has an optimal level of regulatory systems activity, which cannot be said about the female athlete $B$. An increased level of regulatory systems stress of the heart rhythm at rest is noted in the female athlete $B$. 
Table 1. The main parameters of heart rate variability in female runners at rest with different levels of physical training.

\begin{tabular}{lcc}
\hline \multicolumn{1}{c}{ Parameters } & Female athlete A & Female athlete B \\
\hline SDNN (ms) & 89 & 48 \\
AMo (\%) & 23.3 & 46.8 \\
Si (relative units) & 23 & 95 \\
TP (ms2) & 7.87 & 2.53 \\
HF (ms2) & 2.79 & 0.97 \\
LF (ms2) & 3.58 & 0.71 \\
VLF (ms2) & 1.71 & 0.83 \\
Heart rate (beats/min) & 56 & 60 \\
\hline
\end{tabular}

Note: SDNN (ms) - the standard deviation normal to normal, AMo (\%) - amplitude of the mode, HF - high frequency, LF - low frequency, VLF - very low frequency.

The analysis of the obtained data has shown that in all days of researches irrespective of a training microcycle the values of fast regulation FRV (a nervous component) considerably exceed the values of slow regulation SRV (a hormonal component) in the female athlete $A$ at rest. The quantitative ratio of these values at rest varies depending on the physical state and degree of exhaustion of the female athlete (Table 2).

Table 2. Dynamics of the values of fast and slow regulation of heart rhythm in female athlete A during 3 micro-cycles.

\begin{tabular}{|c|c|c|c|c|c|c|c|c|c|c|}
\hline \multirow{2}{*}{ State } & \multicolumn{5}{|c|}{ FRV (\%) } & \multirow{2}{*}{$\begin{array}{c}\text { Mean } \\
\text { FRV }(\%)\end{array}$} & \multicolumn{3}{|c|}{ SRV (\%) } & \multirow{2}{*}{$\begin{array}{c}\text { Mean } \\
\text { SRV (\%) }\end{array}$} \\
\hline & $\mathrm{A} 1$ & B1 & B2 & C1 & D1 & & A2 & $\mathrm{C} 2$ & D2 & \\
\hline \multicolumn{11}{|c|}{1 micro-cycle } \\
\hline \multicolumn{11}{|l|}{ Rest } \\
\hline$x$ & 83.8 & $62.9^{*}$ & 85.2 & 78.8 & 83.4 & 79.2 & 40 & 41.2 & 35.8 & 38.5 \\
\hline$\pm \mathrm{m}$ & 4.8 & 7.7 & 7.1 & 5.1 & 7.1 & 5.3 & 3.4 & 9.5 & 6.4 & 7.7 \\
\hline \multicolumn{11}{|c|}{ After the exercises } \\
\hline$x$ & 77.4 & 36.6 & 70.2 & 79.6 & 77.6 & 68.3 & 34 & 51.4 & 36.6 & 43 \\
\hline $\pm m$ & 5.5 & 5.2 & 8.3 & 2.7 & 5 & 4 & 2.7 & 14.3 & 6.1 & 10 \\
\hline \multicolumn{11}{|c|}{2 micro-cycle } \\
\hline \multicolumn{11}{|l|}{ Rest } \\
\hline$x$ & 74.8 & 50 & 83 & 85.2 & 89.4 & 76.4 & 53.7 & 75 & 48.8 & 61.9 \\
\hline$\pm \mathrm{m}$ & 5.1 & 8.1 & 7.8 & 4.9 & 3.3 & 5.2 & 4.1 & 10.3 & 4.5 & 7.2 \\
\hline
\end{tabular}




\begin{tabular}{|c|c|c|c|c|c|c|c|c|c|c|}
\hline \multicolumn{11}{|c|}{ After the exercises } \\
\hline$x$ & 74.6 & 50 & 83 & 85.2 & 89.4 & 76.4 & 53.4 & 75 & 48.8 & 61.9 \\
\hline $\pm m$ & 5.1 & 8.1 & 7.9 & 4.9 & 3.1 & 5.2 & 4.1 & 10.3 & 4.5 & 7.2 \\
\hline \multicolumn{11}{|c|}{3 micro-cycle } \\
\hline \multicolumn{11}{|l|}{ Rest } \\
\hline$x$ & $84.6^{*}$ & 64 & $86.2^{*}$ & 81.2 & 84.3 & 80.1 & 68.7 & 65.4 & $37.8^{*}$ & $51.7^{*}$ \\
\hline $\pm m$ & 3.8 & 8.4 & 6.5 & 5.3 & 4.7 & 5.6 & 1.4 & 9.4 & 3.9 & 6.4 \\
\hline \multicolumn{11}{|c|}{ After the exercises } \\
\hline$x$ & 63.5 & 35.6 & 65.8 & 74.4 & 69 & 61.8 & 71 & 83 & 53.2 & 68.3 \\
\hline $\pm m$ & 7.2 & 11.5 & 5.7 & 8.9 & 8.7 & 8 & 1.7 & 3.1 & 5.1 & 3.8 \\
\hline
\end{tabular}

Note: * - the reliability of the differences by Student's t-test

It is established that in the normal conditions under the influence of the daily physical training the female athlete $A$ has a decrease in values of the nervous regulation and increase in hormonal regulation. All this indicates the harmonization of the two components of neurohormonal regulation under the normal conditions in the 1st and 2nd micro-cycles. The researches have shown that during the period of considerable body tension with an inadequate physical load of the body state in the 3rd training micro-cycle there is a violation of the relationship between the nervous and hormonal regulation. Thus, the parameters of nervous regulation (A1, B1, B2) increase in the female athlete in the third micro-cycle in comparison with two previous ones, the values of hormonal regulation $(\mathrm{C} 2, \mathrm{D} 2)$ significantly decrease, that indicates the predominance of the nervous and suppression of the hormonal component in the system of neurohormonal regulation. Hence is offered an obvious conclusion that the health of the female athlete and her physical training state are impossible without the maintaining of the distinct harmonization of two parameters of neurohormonal regulation.

Dynamics of the values of fast and slow regulation of heart rhythm in female athlete B during 3 micro-cycles is represented in the Table 3 .

The carried-out auto-correlation analysis has allowed to reveal the corresponding correlation between the intervals of the investigated series. With the help of consistent shifting of $R-R$ intervals relative to each other it was succeeded to receive a number of correlation coefficients and to construct an autocorrelogram. The form of the latter one helped to make a judgment about the wave structure of heart rhythm of the female runners for long distances.

Comparative values of the heart rate regulation in female athletes $A$ and $B$ indicate that the values of slow regulation of heart rhythm in female athlete $B$ are significantly lower than in female athlete $A$. This allowed us to assume that the loadings for the female athlete $B$ were excessive. These assumptions were confirmed by the ECG changes in the II standard lead (the appearance of the negative T wave, an increase of the QRS 
complex, and a decrease in the S-T segment), indicating the development of the impaired myocardial repolarization owing to the beginning of the physical defatigation in the female athlete $B$.

Table 3. Dynamics of the values of fast and slow regulation of heart rhythm in female athlete $B$ during 3 micro-cycles.

\begin{tabular}{|c|c|c|c|c|c|c|c|c|c|c|}
\hline \multirow{2}{*}{ State } & \multicolumn{5}{|c|}{ FRV (\%) } & \multirow{2}{*}{$\begin{array}{c}\text { Mean } \\
\text { FRV } \\
(\%)\end{array}$} & \multicolumn{3}{|c|}{ SRV (\%) } & \multirow{2}{*}{$\begin{array}{c}\text { Mean } \\
\text { SRV } \\
(\%)\end{array}$} \\
\hline & A1 & B1 & B2 & C1 & D1 & & A2 & $\mathrm{C2}$ & D2 & \\
\hline \multicolumn{11}{|c|}{1 micro-cycle } \\
\hline \multicolumn{11}{|l|}{ Rest } \\
\hline$x$ & 88.3 & 59.2 & 61.4 & 60.2 & 60.2 & 65.8 & 45 & 5.5 & 11.2 & 8.4 \\
\hline $\pm m$ & 8.3 & 9.1 & 10.2 & 3.5 & 7.8 & 4.2 & 4.2 & 4.6 & 3.9 & 2.9 \\
\hline \multicolumn{11}{|c|}{ After the exercises } \\
\hline $\mathbf{x}$ & 87.8 & 51.7 & 65.8 & 60.6 & 59.7 & 65.3 & 40 & 12.4 & 19 & 15.7 \\
\hline $\pm m$ & 2.2 & 4.1 & 4.7 & 5 & 8.3 & 2.8 & 3.5 & 6.7 & 4.1 & 4.9 \\
\hline \multicolumn{11}{|c|}{2 micro-cycle } \\
\hline \multicolumn{11}{|l|}{ Rest } \\
\hline$x$ & $98.6^{*}$ & $67.2^{*}$ & 54.6 & $62.6^{*}$ & 47.6 & $67.1^{*}$ & 75.6 & 0.8 & 14.7 & 7.8 \\
\hline $\pm m$ & 1.2 & 6.7 & 4.2 & 3.8 & 8.7 & 4.3 & 1.2 & 0.4 & 0.8 & 0.4 \\
\hline \multicolumn{11}{|c|}{ After the exercises } \\
\hline $\mathrm{x}$ & 83.6 & 40.2 & 48.8 & 50 & 33.8 & 51.3 & 73 & 2.6 & 17.8 & 10.3 \\
\hline $\pm m$ & 4.7 & 4.4 & 3.6 & 3.9 & 6.6 & 4.2 & 2.4 & 1.1 & 2.1 & 1.5 \\
\hline \multicolumn{11}{|c|}{3 micro-cycle } \\
\hline \multicolumn{11}{|l|}{ Rest } \\
\hline$x$ & $99.1^{*}$ & 77.8 & 64 & 65 & 59.2 & 72.6 & 67.3 & 0 & 13.5 & 8.8 \\
\hline $\pm m$ & 0.6 & 3.1 & 2.5 & 3.2 & 3.6 & 1.2 & 0.8 & 0 & 1.2 & 2.5 \\
\hline \multicolumn{11}{|c|}{ After the exercises } \\
\hline$x$ & 94.2 & 66.3 & 67 & 56 & 62 & 69.1 & 65.5 & 0 & 15.3 & 7.6 \\
\hline $\pm m$ & 1.8 & 5.6 & 4.7 & 3.4 & 8.5 & 4.1 & 0.9 & 0 & 2.2 & 1.1 \\
\hline
\end{tabular}

Note: * - the reliability of the differences by Student's t-test

\section{CONCLUSIONS}

In the course of the studies it was found that after the test with the controlled physical load the female athlete $A$ had a significantly reduced recovery time of respiratory waves compared to the female athlete $\mathrm{B}$. It demonstrates that the recovery time rate of respiratory waves in a more physically trained female athlete was significantly higher in comparison with the female athlete $B$, who initially had a lower training level.

The recovery rate value of respiratory waves after the controlled load can be recommended for assessing the adaptation degree of female runners for the long distances. 


\section{REFERENCES}

Bakaev, V.V., Bolotin, A.E., \& Vasil'eva, V.S. (2015). Factors determining sports specialization of cross country skiers. Teoriya i Praktika Fizicheskoy Kultury, (2), 40-41.

Bakaev, V.V., Bolotin, A.E., \& Aganov, S.S. (2016). Physical training complex application technology to prepare rescuers for highland operations. Teoriya i Praktika Fizicheskoy Kultury, (6), 6-8.

Bolotin, A, \& Bakayev V. (2017). Peripheral circulation indicators in veteran trail runners. Journal of Physical Therapy Science, 29(6), 1092-1094. https://doi.org/10.1589/jpts.29.1092

Bolotin, A. \& Bakayev V. (2016). Factors that determine high efficiency in developing speed and strength abilities of female hurdlers. Journal of Physical Education and Sport, 16(3), 910-913.

Bolotin, A. \& Bakayev V. (2017). Method for Training of Long Distance Runners Taking into Account Bioenergetic Types of Energy Provision for Muscular Activity. In Proceedings of the 5th International Congress on Sport Sciences Research and Technology Support, 126-131. https://doi.org/10.5220/0006516101260131

Bunevicius, K, Sujeta A, Poderiene K, et al. (2016). Cardiovascular response to bouts of exercise with blood flow restriction. Journal of Physical Therapy Science, 29(12), 3288-3292. https://doi.org/10.1589/jpts.28.3288

Cooper, K (1989). The aerobics program for total well-being. Physical Education and Sport, Moscow, $224 \mathrm{p}$.

Daniel, S. (2009). Abnormal blood flow in the sublingual microcirculation at high altitude / S. Daniel// Eur. J. Appl. Physiol., (106), 473-478.

Hopkins, W., Marshall, S., Batterham, A., \& Hanin, J. (2009). Progressive statistics for studies in sports medicine and exercise science. Medicine \& Science in Sports \& Exercise, 41(1), 3-12. https://doi.org/10.1249/MSS.0b013e31818cb278

Khimenes, K., Lynets, M., Yuriy, B., Maryan, P., \& Galan, Y. (2016). Improvement of sportsmen's physical fitness during previous basic training (based on sport orienteering material). Journal of Physical Education and Sport, 16(2), 392-396. https://doi.org/10.7752/jpes.2016.02061

Matveyev, L. (1981). Fundamentals of sports training. Moscow: Progress.

Pityn M., Briskin Y., Perederiy A., Galan Y., Tsyhykalo O., Popova I. (2017). Sport specialists' attitude to structure and contents of theoretical preparation in sport. Journal of Physical Education and Sport, 17, Supplement issue 3, 988-994. https://doi.org/10.7752/jpes.2017.s3152

Willardson, J. M. (2007). Core stability training: Applications to sports conditioning programs. The Journal of Strength \& Conditioning Research, 21(3), 979-985. https://doi.org/10.1519/00124278-200708000$\underline{00054}$

\section{(2) $\mathbb{Q} \Theta \Theta$}

This title is licensed under a Creative Commons Attribution-NonCommercial-NoDerivs 4.0 Unported License. 